\title{
Dysphagia and its impact on the quality of life of head and neck cancer patients: institution-based cross-sectional study
}

\author{
Tseganesh Asefa Yifru', Sezer Kisa², Negalign Getahun Dinegde ${ }^{3}$ and Niguse Tadele Atnafu ${ }^{4^{*}}$ (D)
}

\begin{abstract}
Objective: Impaired swallowing is a primary medical concern in head and neck cancer (HNC) patients. Swallowing therapy and supportive care to relieve swallowing problems among HNC patients are recommended. However, no data shows the effect of dysphagia on the quality of life (QoL) among Ethiopian patients. This cross-sectional study aimed to assess swallowing function and its impact on QoL.

Results: The sample included 102 HNC patients who visited oncology clinics at Tikur Anbessa Specialized Hospital. Majority were male (53.90\%), employed (70.6\%), single (57.80\%), and completed some level of formal education (66.60\%) with a mean age of 42.58 years (SD \pm 14.08 ). More than half of the patients (69.6\%) medical expenses were covered by the government. Most were suffering from advanced stage HNC (59.80\%), squamous cell carcinoma (62.70\%), and the most prevalent tumor location was nasopharynx (40.20\%). The mean MDADI score was 53.29 (SD \pm 15.85$)$. Being female, low income, suffering from laryngeal cancer, advanced tumor, and undergoing a single modality therapy were crucial determinants of poor QoL related to swallowing problems. It is recommended to assess swallowing related QoL of patients using a validated tool and be included in treatment protocols.
\end{abstract}

Keywords: Dysphagia, Head and neck cancer, Impaired swallowing, MDADI, Quality of life

\section{Introduction}

Dysphagia is a frequent sequel of $\mathrm{HNC}$ and its treatment. Patients report significant difficulty eating solid foods, swallowing, choking, coughing after the swallow, spending more time consuming food and weight loss which exacerbate with treatment intensification. HNC also has a profound impact on the social well-being of patients, such as altered social interactions, loss of enjoyment with eating, embarrassment, and dissatisfaction throughout treatment and even after completion of a therapy [1-3].

Factors predictive of poor QoL due to dysphagia include patient-related factors such as smoking, age and

\footnotetext{
${ }^{*}$ Correspondence: niguse.tadele@aau.edu.et

${ }^{4}$ Department of Nursing, School of Nursing \& Midwifery, College of Health Sciences, Addis Ababa University, Addis Ababa, Ethiopia Full list of author information is available at the end of the article
}

gender [1, 4-9]; tumor-related factors such as advanced tumor stage [10-12] and factors related to tumor location $[11,13]$. It is well established in the literature that patients with tongue [13, 14], buccal [12] and hypopharyngeal $[10,15,16]$ tumors had worse dysphagia related QoL. Patients who have had radiotherapy treatment [6, 17-19], HNC surgery [20], and concomitant chemotherapy [13] had higher levels of dysphagia and dietary problems that indicate lower QoL. Deterioration in swallowing function affects the patient's QoL multidimensional throughout the course of a treatment [21].

Studies highlight the need for assessing the QoL of cancer patients for a good understanding of the degree of improvement obtained with therapeutic procedures. Despite this fact, no study in Ethiopia assessed this association, and therefore, this study analyzed the association

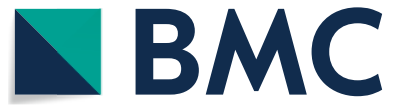

(C) The Author(s) 2021. This article is licensed under a Creative Commons Attribution 4.0 International License, which permits use, sharing, adaptation, distribution and reproduction in any medium or format, as long as you give appropriate credit to the original author(s) and the source, provide a link to the Creative Commons licence, and indicate if changes were made. The images or other third party material in this article are included in the article's Creative Commons licence, unless indicated otherwise in a credit line to the material. If material is not included in the article's Creative Commons licence and your intended use is not permitted by statutory regulation or exceeds the permitted use, you will need to obtain permission directly from the copyright holder. To view a copy of this licence, visit http://creativeco mmons.org/licenses/by/4.0/. The Creative Commons Public Domain Dedication waiver (http://creativecommons.org/publicdomain/ zero/1.0/) applies to the data made available in this article, unless otherwise stated in a credit line to the data. 
between dysphagia and QoL among patients undergoing treatment for $\mathrm{HNC}$ in Ethiopia.

\section{Main text \\ Methods}

Patients and sampling strategy This cross-sectional study population included male and female adult head and neck cancer survivors who visited oncology clinics at Tikur Anbessa Specialized Hospital from February to April 2019. Patients who are $\geq 18$ years, had no evident cognitive impairment and an eating disorder were selected using a consecutive sampling method and included in the study.

The sample size was estimated using the population adjustment formula for single proportion estimation based on a $95 \%$ confidence level, a precision of $5 \%$, and $50 \%$ expected prevalence. Since there was no prior study and a $10 \%$ non-response, yielding a total sample of 109 head and neck cancer patients.

\section{Data collection tools}

Document review Patient charts were reviewed to identify patients with HNC and extract clinical characteristics such as diagnosis, primary cancer site, cancer stage, type of carcinoma, and treatment type.

\section{Self-reported questionnaire}

A self-reported questionnaire was also used to collect information on patients' socio-demographics such as age, sex, marital status, level of education, working condition, residence, income, and modality of payment coverage for medical expenses.

\section{The MD Anderson Dysphagia Inventory (MDADI)}

An Amharic version of the MDADI questionnaire (20item psychometrically validated and reliable) is specifically developed to evaluate dysphagia's impact on the QoL of patients with HNC [22], was used. All questions (except E7 and F2) has five possible responses (strongly agree, agree, no opinion, disagree, and strongly disagree) and scores from 1 (strongly agree) to 5 (strongly disagree). The Global domain is shown separately. The composite mean score is obtained by adding the other three domains, calculating their mean, and multiplying this by 20 . The composite mean score ranged from 20 (extremely low functioning) to 100 (high functioning).

\section{Statistical analysis}

This measure's overall reliability was determined to be very good (Cronbach's coefficient alpha $=0.924)$, and the subscale also had acceptable internal consistency (emotional, 0.79; functional, 0.71; physical, 0.89).
Questionnaire responses were used to construct categorical variables. Patients diagnosed with cancer within six months before data collection were defined as 'newly diagnosed, 'and patients who were divorced, widowed, separated, and never married are categorized as 'single.' The level of income was determined based on their ability to cover their medical expenses. Patients were classified as 'fee-paying' if they were economically able to pay their medical expenses, and those involved in any income-generating activity were categorized as employed. Furthermore, patients who took any combination of treatment modalities were categorized under 'Multi-modality treatment,' and cancer stages III \& IV were categorized under 'Advanced.'

Descriptive statistics were used to analyze the demographic and clinical characteristics of participants. Besides, the independent t-test (for two groups) and one-way ANOVA (for more than two groups) were used to compare means between the demographic and clinical features with four domains, and the composite mean score of the MDADI and $P<0.05$ was considered significant. Once it was determined that differences exist among the means, post hoc range tests and multiple pairwise comparisons were conducted to determine which means differ. All statistical tests were performed using version 24 SPSS (Statistical Package for Social Sciences).

\section{Results}

\section{Patient characteristics}

The study population consisted of $102 \mathrm{HNC}$ patients (93.6\% response rate), mostly males $(53.90 \%)$, employed (70.6\%), single (57.80\%), and completed some level of formal education $(66.60 \%)$ with a mean age of 42.58 years ( $\mathrm{SD} \pm 14.08$ years). The majority $(69.6 \%)$ belonged to extremely low economic status, and the government covered their medical expense. Most were suffering from advanced stage HNC (59.80\%), and squamous cell carcinoma $64(62.70 \%)$, and the prevalent tumor location was nasal cavity/ nasopharynx carcinoma (40.20\%), and about $34.3 \%$ of patients were newly diagnosed. Combination of treatment modalities, including chemotherapy, radiation therapy, and surgery, was the most prevalent type of treatment in which $55.90 \%$ of the patients had this all treatments (Additional file 1: Tables S1 and S2).

\section{MDADI scores}

The composite mean MDADI score of 53.29 (15.85) and overall question score of 53.34 (16.96) was found, and the lowest scores were found for the global score (44.51) and physical domain (49.4) (Additional file 1: Tables S3).

Tables 1 and 2 shows the mean differences in MDADI scores among different groups. Among socio-demographic characteristics, women had a significantly lower 
Table 1 Mean differences of MDADI subscales according to socio demographic characteristics of participants

\begin{tabular}{|c|c|c|c|c|c|c|}
\hline \multirow[t]{2}{*}{ Variable } & \multicolumn{6}{|c|}{ MDADI (Mean \pm SD) } \\
\hline & All questions & Composite mean & Global & Emotional & Functional & Physical \\
\hline \multicolumn{7}{|l|}{ Sex } \\
\hline Male & $56.3 \pm 18.5$ & $56.3 \pm 16.6$ & $47.6 \pm 25.1$ & $58.7 \pm 18.9$ & $61.2 \pm 17.6$ & $52.6 \pm 21.3$ \\
\hline Female & $49.8 \pm 14.4$ & $49.7 \pm 14.3$ & $40.8 \pm 19.9$ & $54.3 \pm 15.3$ & $53.6 \pm 16.8$ & $45.7 \pm 15.9$ \\
\hline P & 0.054 & 0.036 & 0.139 & 0.204 & 0.030 & 0.069 \\
\hline \multicolumn{7}{|l|}{ Age in years } \\
\hline $18-43$ & $50.7 \pm 16.0$ & $51.6 \pm 14.9$ & $41.8 \pm 22.6$ & $53.7 \pm 17.1$ & $55.3 \pm 17.7$ & $47.1 \pm 17.8$ \\
\hline Above 43 & $56.5 \pm 17.7$ & $55.3 \pm 16.8$ & $47.8 \pm 23.3$ & $60.2 \pm 17.3$ & $60.5 \pm 17.0$ & $52.3 \pm 20.7$ \\
\hline P & 0.086 & 0.241 & 0.189 & 0.060 & 0.140 & 0.169 \\
\hline \multicolumn{7}{|l|}{ Marital status } \\
\hline Living alone & $55.4 \pm 16.8$ & $54.7 \pm 15.5$ & $47.8 \pm 24.4$ & $58.9 \pm 17.3$ & $59.3 \pm 16.8$ & $51.5 \pm 19.1$ \\
\hline Living with partner & $50.4 \pm 16.9$ & $51.4 \pm 16.3$ & $40.0 \pm 20.5$ & $53.6 \pm 17.4$ & $55.5 \pm 18.5$ & $46.6 \pm 19.4$ \\
\hline$P$ & 0.141 & 0.301 & 0.091 & 0.130 & 0.292 & 0.210 \\
\hline \multicolumn{7}{|l|}{ Level of education } \\
\hline No formal education & $52.7 \pm 14.7$ & $53.3 \pm 13.6$ & $44.7 \pm 20.3$ & $55.2 \pm 15.6$ & $56.0 \pm 15.0$ & $49.8 \pm 16.8$ \\
\hline Primary & $50.6 \pm 14.8$ & $50.4 \pm 13.9$ & $39.2 \pm 20.8$ & $53.9 \pm 15.8$ & $53.2 \pm 17.0$ & $48.0 \pm 16.5$ \\
\hline Secondary & $54.1 \pm 22.5$ & $52.9 \pm 21.2$ & $50.0 \pm 28.5$ & $57.2 \pm 21.5$ & $60.7 \pm 20.1$ & $48.1 \pm 25.7$ \\
\hline Higher & $56.2 \pm 17.8$ & $56.3 \pm 16.5$ & $45.4 \pm 24.4$ & $60.6 \pm 18.3$ & $62.0 \pm 18.8$ & $51.3 \pm 20.5$ \\
\hline P & 0.705 & 0.630 & 0.508 & 0.534 & 0.263 & 0.929 \\
\hline \multicolumn{7}{|l|}{ Employment status } \\
\hline Employed $^{\mathrm{a}}$ & $54.8 \pm 17.6$ & $54.4 \pm 16.6$ & $46.9 \pm 24.5$ & $58.0 \pm 17.9$ & $59.3 \pm 17.6$ & $50.8 \pm 20.4$ \\
\hline Unemployed & $49.9 \pm 14.9$ & $50.6 \pm 13.7$ & $38.7 \pm 18.1$ & $53.3 \pm 15.9$ & $53.9 \pm 17.1$ & $46.3 \pm 16.1$ \\
\hline P & 0.187 & 0.263 & 0.098 & 0.219 & 0.157 & 0.283 \\
\hline \multicolumn{7}{|l|}{ Place of residence } \\
\hline Addis Ababa & $48.8 \pm 17.1$ & $49.1 \pm 17.7$ & $39.2 \pm 22.9$ & $52.9 \pm 17.5$ & $55.1 \pm 19.1$ & $43.8 \pm 20.3$ \\
\hline Regional /rural & $54.9 \pm 16.7$ & $54.7 \pm 15.0$ & $46.3 \pm 22.9$ & $57.9 \pm 17.4$ & $58.6 \pm 17.0$ & $51.4 \pm 18.6$ \\
\hline$P$ & 0.118 & 0.119 & 0.177 & 0.214 & 0.382 & 0.081 \\
\hline \multicolumn{7}{|c|}{ Level of income/medical expenses coverage } \\
\hline Fee paying & $60.7 \pm 19.7$ & $58.9 \pm 19.8$ & $50.9 \pm 25.7$ & $64.3 \pm 17.9$ & $65.7 \pm 19.3$ & $56.8 \pm 24.2$ \\
\hline Covered by government & $50.1 \pm 14.6$ & $50.8 \pm 13.2$ & $41.7 \pm 21.3$ & $53.3 \pm 16.2$ & $54.2 \pm 15.6$ & $46.2 \pm 15.8$ \\
\hline P & $0.003^{*}$ & $0.018^{*}$ & 0.061 & $0.003^{*}$ & $0.002^{*}$ & $0.010^{*}$ \\
\hline \multicolumn{7}{|l|}{ Smoking } \\
\hline Yes & $52.3 \pm 15.4$ & $52.4 \pm 14.9$ & $43.4 \pm 22.2$ & $56.4 \pm 15.6$ & $56.6 \pm 16.6$ & $47.9 \pm 17.8$ \\
\hline No & $57.5 \pm 22.3$ & $56.8 \pm 19.5$ & $49.0 \pm 26.3$ & $57.5 \pm 24.1$ & $62.0 \pm 21.0$ & $55.6 \pm 24.0$ \\
\hline$P$ & 0.229 & 0.266 & 0.333 & 0.806 & 0.222 & 0.109 \\
\hline
\end{tabular}

$t$ test (for two groups comparison) and one-way ANOVA (for three and above group comparison) were employed, *Significant at $p$ value less than 0.05

composite mean $(p=0.036)$ and functional $(p=0.030)$ scale scores. Patients who were economically able to pay for their medical expenses had significantly higher composite mean scores in all MDADI domains except the global domain. Other socio-demographic variables, including age, marital status, level of education, employment status, residence, and smoking habit, did not differ between each domain (Table 1).

Regarding clinical features, statistically significant mean differences were observed between different primary tumor sites in all domains except the emotional and functional domains. In addition, patients with initial tumor stages (TI and II) had better scores in total questions $(p=0.042)$, composite mean score $(p=0.019)$, global $(p=0.024)$. and functional $(p=0.049)$ domains, while worse scores in the physical domain $(p=0.054)$ were observed among patients undergoing single modality treatment. Time since diagnosis and type of carcinoma did not differ between each domain (Table 2).

Compared with patients with oral cavity/ oropharyngeal cancer, those patients with laryngeal/ hypo pharyngeal cancer had significantly lower score in total 
Table 2 Mean differences of MDADI subscales according to clinical and treatment variables of participants

\begin{tabular}{|c|c|c|c|c|c|c|}
\hline \multirow[t]{2}{*}{ Variable } & \multirow[b]{2}{*}{ All questions } & \multicolumn{5}{|c|}{ MDADI (Mean \pm SD) } \\
\hline & & Composite mean & Global & Emotional & Functional & Physical \\
\hline \multicolumn{7}{|l|}{ Time since diagnosis } \\
\hline New & $52.1 \pm 17.1$ & $51.9 \pm 15.4$ & $44.6 \pm 24.3$ & $55.9 \pm 16.9$ & $56.5 \pm 17.9$ & $47.4 \pm 19.0$ \\
\hline 6-12 months & $52.9 \pm 17.4$ & $53.1 \pm 16.2$ & $46.7 \pm 24.4$ & $54.4 \pm 18.9$ & $55.8 \pm 17.2$ & $50.7 \pm 18.9$ \\
\hline More than year ago & $55.3 \pm 16.6$ & $55.1 \pm 16.3$ & $41.9 \pm 20.2$ & $60.1 \pm 16.2$ & $61.3 \pm 17.4$ & $50.2 \pm 20.3$ \\
\hline$P$ & 0.729 & 0.333 & 0.707 & 0.389 & 0.389 & 0.749 \\
\hline \multicolumn{7}{|l|}{ Primary tumor site } \\
\hline Oral cavity/Oropharyngeal & $57.4 \pm 20.8$ & $57.4 \pm 18.4$ & $52.0 \pm 28.1$ & $59.3 \pm 20.9$ & $60.7 \pm 20.5$ & $54.5 \pm 22.8$ \\
\hline Nasal cavity/Nasopharyngeal & $55.0 \pm 16.4$ & $54.7 \pm 16.1$ & $43.9 \pm 21.1$ & $59.0 \pm 16.4$ & $59.9 \pm 16.9$ & $50.8 \pm 19.8$ \\
\hline Larynx/ Hypo pharyngeal & $47.2 \pm 11.5$ & $47.5 \pm 11.2$ & $38.1 \pm 18.2$ & $50.9 \pm 13.8$ & $51.9 \pm 14.1$ & $42.7 \pm 12.2$ \\
\hline$P$ & $0.044^{*}$ & $0.040^{*}$ & $0.058^{*}$ & 0.086 & 0.084 & $0.045^{*}$ \\
\hline \multicolumn{7}{|l|}{ Tumor T stage } \\
\hline Initial & $57.5 \pm 18.2$ & $57.7 \pm 15.8$ & $50.7 \pm 24.9$ & $60.5 \pm 18.4$ & $61.8 \pm 16.8$ & $53.4 \pm 20.8$ \\
\hline Advanced & $50.6 \pm 15.6$ & $50.3 \pm 15.3$ & $40.3 \pm 20.8$ & $54.0 \pm 16.4$ & $54.9 \pm 17.6$ & $46.8 \pm 17.9$ \\
\hline$P$ & $0.042^{*}$ & $0.019^{*}$ & $0.024^{*}$ & 0.067 & $0.049^{*}$ & 0.092 \\
\hline \multicolumn{7}{|l|}{ Type of carcinoma } \\
\hline Squamous cell & $53.0 \pm 16.6$ & $53.3 \pm 15.8$ & $44.4 \pm 22.1$ & $56.0 \pm 17.8$ & $57.2 \pm 17.2$ & $49.5 \pm 18.8$ \\
\hline Adenocarcinoma & $55.6 \pm 19.5$ & $54.7 \pm 17.4$ & $48.7 \pm 25.5$ & $58.3 \pm 18.9$ & $60.2 \pm 20.2$ & $51.5 \pm 22.0$ \\
\hline Other & $51.3 \pm 15.1$ & $51.2 \pm 14.4$ & $38.7 \pm 23.3$ & $56.7 \pm 13.9$ & $56.0 \pm 15.0$ & $45.8 \pm 17.2$ \\
\hline$P$ & 0.730 & 0.803 & 0.425 & 0.874 & 0.725 & 0.676 \\
\hline \multicolumn{7}{|l|}{ Treatment modality } \\
\hline Single modality treatment & $50.5 \pm 14.7$ & $50.1 \pm 14.0$ & $40.9 \pm 20.7$ & $55.4 \pm 15.9$ & $55.7 \pm 16.9$ & $45.2 \pm 16.7$ \\
\hline Multi-modality treatment & $55.5 \pm 18.3$ & $55.8 \pm 16.9$ & $47.2 \pm 24.5$ & $57.5 \pm 18.6$ & $59.2 \pm 17.9$ & $52.6 \pm 20.6$ \\
\hline$P$ & 0.148 & 0.072 & 0.170 & 0.555 & 0.328 & 0.054 \\
\hline
\end{tabular}

$t$-test (for two groups comparison) and one-way ANOVA (for three and above group comparison) were employed, *Significant at $p$ value less than 0.05

questions $(p=0.048)$, composite mean score $(p=0.039)$, global $(p=0.047)$ and physical $(p=0.042)$ domains (Table 3).

\section{Discussion}

This study aimed to assess dysphagia's impact on the quality of life domains of the MD Anderson Dysphagia

Table 3 Multiple comparisons (Tukey HSD) between primary tumor site

\begin{tabular}{|c|c|c|c|c|c|c|}
\hline \multirow[t]{2}{*}{ Dependent variable } & \multirow[t]{2}{*}{ Primary tumor site } & \multirow[t]{2}{*}{ Primary tumor site } & \multirow[t]{2}{*}{ Mean difference } & \multirow[t]{2}{*}{$P$} & \multicolumn{2}{|l|}{$95 \% \mathrm{Cl}$} \\
\hline & & & & & Lower & Upper \\
\hline \multirow[t]{3}{*}{ Total questions } & Oral cavity & Nasal cavity & 2.3 & .830 & -7.2 & 11.8 \\
\hline & & Larynx & $10.2^{*}$ & .048 & 0.1 & 20.3 \\
\hline & Nasal cavity & Larynx & 7.9 & .120 & -1.6 & 17.3 \\
\hline \multirow[t]{3}{*}{ Composite mean } & Oral cavity & Nasal cavity & 2.7 & .748 & -6.2 & 11.6 \\
\hline & & Larynx & $9.8^{*}$ & .039 & 0.4 & 19.3 \\
\hline & Nasal cavity & Larynx & 7.1 & .135 & -1.7 & 15.9 \\
\hline \multirow[t]{3}{*}{ Global } & Oral cavity & Nasal cavity & 8.1 & .299 & -4.8 & 21.0 \\
\hline & & Larynx & $13.9^{*}$ & .047 & 0.2 & 27.7 \\
\hline & Nasal cavity & Larynx & 5.8 & .525 & -7.0 & 18.6 \\
\hline \multirow[t]{3}{*}{ Physical } & Oral cavity & Nasal cavity & 3.7 & .701 & -7.1 & 14.4 \\
\hline & & Larynx & $11.8^{*}$ & .042 & 0.4 & 23.3 \\
\hline & Nasal cavity & Larynx & 8.2 & .167 & -2.5 & 18.9 \\
\hline
\end{tabular}

\footnotetext{
* The mean difference is significant at the 0.05 level
} 
Inventory among 102 head and neck cancer patients. We found a composite mean of 53.29 in the MDADI, reflecting a mean reduction in the QoL due to swallowing changes. The majority of patients in this study reported that their swallowing limits their daily activities.

The composite MDADI mean scores in this study were considerably lower than reported in Brazil (63.36) $[3,23,24]$, the USA $(64.06$ and 67$)[10,23,24]$, and Taiwan (67.08) [25], indicating the severity of this problem in Ethiopia. The variation may be due to the fact that patients in Ethiopia lack access to early treatment and support since there is a single cancer center in the country that provides comprehensive cancer care.

Similar to previous studies, factors such as gender [6], financial burden [26], tumor stage [27], location of HNC [18], and type of treatment [13, 14], this study also identified female sex, low income, suffering from hypopharyngeal cancer, and advanced tumor as the critical determinants of poor QoL related to swallowing problems among HNC patients. These results have direct implications for improving the care of $\mathrm{HNC}$ patients by highlighting the need to incorporate swallowing function in the assessment and clinical management of patients.

In contrast to previous studies that reported factors such as age [11, 17, 28], marital status [15], smoking [6, $18-20]$, and deterioration in swallowing function through time [12], no associations were observed between age, smoking habit, marital status, time since diagnosis and type of carcinoma in this study.

Female cancer patients in this study experienced poor swallowing related QoL consistent with earlier studies $[11,13]$. Women were more emotionally distressed, frustrated, embarrassed, and depressed due to the inability to enjoy mealtime [29] compared with their male counterparts.

In this study, low-income patients scored lower MDADI scores in most of the domains, consistent with the previous studies that linked financial burden from cancer with poor QoL $[10,11]$.

Our results were consistent with prior studies that identified the negative impact of cancer stage and location on swallowing related QoL. It is interesting to note that worse MDADI scores among patients with advanced tumor stages and had hypopharyngeal tumors observed in prior studies [10,23,24]. The literature results were consistent with the risk observed for lower QoL scores in our population. Patients with oral cavity/ oropharyngeal tumor and at initial tumor stages had better MDADI scores than patients with hypopharyngeal and advancedstage cancer, emphasizing the need to rigorously address swallowing function in such cancer patients.

Unlike the finding of studies done in Spain, Brazil, and the USA [13, 14], those patients who received a multi-modality treatment were found to have better scores than those with single-modality treatment. This difference might be related to the fact that those patients with advanced stage cancer were less likely to had surgery and radiotherapy, and any form of combination therapy due to their condition.

\section{Conclusion}

In this cross-sectional study, patients with head and neck cancer had an impaired swallowing related quality of life. This study identifies factors associated with impaired swallowing related quality of life, such as gender (male), marital status (living alone), patient residence distance from the treatment center, and medical expense.

Therefore, future studies should separately address therapy's effect on swallowing problems for patients with early and advanced stage HNC patients in Ethiopia. As the burden of swallowing difficulties in HNC patients was established, it is crucial to incorporate swallowing function in routine cancer therapy protocols to mitigate dysphagia's effect on QoL.

\section{Strengths and limitations}

To our knowledge, this study was the first in Ethiopia that assessed the effect of dysphagia on QoL and identified associated factors for poor dysphagia related QoL in HNC patients. It provided baseline data that are essential to evaluate the progress of swallowing function in HNC patients. However, some limitations of this study warrant caution in interpreting the results. Mainly, the cross-sectional nature of this study does not allow drawing any causal inferences. However, owing to the absence of literature in this area, our results could direct future studies by allowing hypothesis generation and providing useful information to target vulnerable populations. As self-reporting was used to collect patient data, our study was prone to recall bias. Furthermore, our questionnaire tailored to account for Ethiopian patients' cultural sensitivities may not be suitable for broader adoption without further validation.

\section{Supplementary Information}

The online version contains supplementary material available at https://doi.
org/10.1186/s13104-020-05440-4.

Additional file 1: Table S1. Socio Demographic Characteristics of Participants. Table S2. Clinical Characteristics of Participants. Table S3. Mean and Standard Deviation of MDADI.

\section{Abbreviations}

ANOVA: Analysis of Variance; ETB: Ethiopian Birr; HNC: Head and neck cancer; MDADI: MD Anderson Dysphagia inventory; QoL: Quality of Life, SD: Standard Deviations; SPSS: Statistical Package for the Social Sciences; USA: United States of America. 


\section{Acknowledgements}

We would like to acknowledge the support of Addis Ababa University by funding this study and patients who respond to our questions.

\section{Authors' contributions}

TA SK NG NT were involved in the conception and design of this study. TA and NT designed the final model and performed the experiments. TA completed final data analysis and wrote the first draft of the manuscript. All authors read and approved the final manuscript.

\section{Funding}

This study was funded by Addis Ababa University, College of Health Sciences, School of Nursing and Midwifery, Department of Nursing.

\section{Availability of data and materials}

The datasets used in this study are available upon request.

\section{Ethics approval and consent to participate}

A written informed consent was obtained from all the participants and we obtained the author permission to use the questionnaire. The study received ethical approval from the Institutional Review Board of College of Health Sciences, School of Nursing and Midwifery (8/19/SNM).

\section{Consent for publication}

Not applicable.

\section{Competing interests}

The authors declare that they have no competing interests.

\section{Author details}

${ }^{1}$ School of Nursing, College of Medicine and Health Sciences, University of Gondar, Gondar, Ethiopia. ${ }^{2}$ Department of Nursing and Health Promotion, Faculty of Health Sciences, Oslo Metropolitan University, Oslo, Norway. ${ }^{3}$ Department of Nursing, School of Nursing \& Midwifery, College of Health Sciences, Addis Ababa University, Addis Ababa, Ethiopia. ${ }^{4}$ Department of Nursing, School of Nursing \& Midwifery, College of Health Sciences, Addis Ababa University, Addis Ababa, Ethiopia.

\section{Received: 11 November 2020 Accepted: 29 December 2020} Published online: 07 January 2021

\section{References}

1. Ottosson S, Laurell G, Olsson C. The experience of food, eating and meals following radiotherapy for head and neck cancer: a qualitative study. J Clin Nurs. 2013;22(7-8):1034-43.

2. Patterson JM, McColl E, Wilson J, Carding P, Rapley T. Head and neck cancer patients' perceptions of swallowing following chemoradiotherapy. Support Care Cancer. 2015;23(12):3531-8.

3. da Silva BAMS. Childhood traumatic events are associated with occurrence of emotional disorders and clinicopathological variables in head and neck cancer patients, Master thesis. 2017. https://repositorio.unesp .br/handle/11449/151620

4. Ames JA, Karnell LH, Gupta AK, Coleman TC, Karnell MP, Van Daele DJ, et al. Outcomes after the use of gastrostomy tubes in patients whose head and neck cancer was managed with radiation therapy. Head Neck. 2011;33(5):638-44.

5. Erinoso O, Okoturo E, Gbotolorun O, Effiom O, Awolola N, Soyemi S, et al. Emerging trends in the epidemiological pattern of head and neck cancers in Lagos, Nigeria. Ann Med Health Sci Res. 2016;6(5):301-7.

6. Frowen J, Drosdowsky A, Perry A, Corry J. Long-term swallowing after chemoradiotherapy: prospective study of functional and patientreported changes over time. Head Neck. 2016;38(S1):E307-15.

7. Ganzer H, Rothpletz-Puglia P, Byham-Gray L, Murphy BA, Touger-Decker R. The eating experience in long-term survivors of head and neck cancer: a mixed-methods study. Support Care Cancer. 2015;23(11):3257-68.

8. Nund RL, Ward EC, Scarinci NA, Cartmill B, Kuipers P, Porceddu SV. Survivors' experiences of dysphagia-related services following head and neck cancer: Implications for clinical practice. Int J Lang Commun Disord. 2014:49(3):354-63.
9. Vesela J, Grebenova S. The influence of psychological and social aspect on the eating habits of primary school children. School Health. 2010;21:271-84.

10. Goepfert RP, Lewin JS, Barrow MP, Fuller CD, Lai SY, Song J, et al. Predicting two-year longitudinal MD Anderson Dysphagia Inventory outcomes after intensity modulated radiotherapy for locoregionally advanced oropharyngeal carcinoma. Laryngoscope. 2017;127(4):842-8. https://doi. org/10.1002/lary.26153.

11. Reeve BB, Cai J, Zhang H, Weissler MC, Wisniewski K, Gross H, et al. Factors that impact health-related quality of life over time for individuals with head and neck cancer. Laryngoscope. 2016;126(12):2718-25.

12. Starmer H, Sanguineti G, Marur S, Gourin CG. Multidisciplinary head and neck cancer clinic and adherence with speech pathology. Laryngoscope. 2011;121(10):2131-5. https://doi.org/10.1002/lary.21746.

13. Pierre CS, Dassonville O, Chamorey E, Poissonnet G, Riss J-C, Ettaiche M, et al. Long-term functional outcomes and quality of life after oncologic surgery and microvascular reconstruction in patients with oral or oropharyngeal cancer. Acta Otolaryngol. 2014;134(10):1086-93.

14. San SW, Ahmad A, Mahadevan B. The swallowing ability and psychosocial domains of patients with dysphagia among head and neck cancer population. JSKM. 2018. https://doi.org/10.17576/jskm-2019-1701-01.

15. Chen S-C, Huang B-S, Chung C-Y, Lin C-Y, Fan K-H, Chang JT-C, et al. Effects of a swallowing exercise education program on dysphagia-specific health-related quality of life in oral cavity cancer patients post-treatment: a randomized controlled trial. Support Care Cancer. 2018;26:1-10.

16. Robertson SM, Yeo JCL, Sabey L, Young D, Mackenzie K. Effects of tumor staging and treatment modality on functional outcome and quality of life after treatment for laryngeal cancer. Head Neck. 2013;35(12):1759-63. https://doi.org/10.1002/hed.23230.

17. Baxi SS, Salz T, Xiao H, Atoria CL, Ho A, Smith-Marrone S, et al. Employment and return to work following chemoradiation in patient with HPVrelated oropharyngeal cancer. Cancers Head Neck. 2016;1 (1):4.

18. Chen S-C, Huang B-S, Hung T-M, Chang Y-L, Lin C-Y, Chung C-Y, et al. Swallowing ability and its impact on dysphagia-specific health-related QOL in oral cavity cancer patients post-treatment. Eur J Oncol Nurs. 2018;36:89-94.

19. Daugaard R, Kjaer T, Johansen C, Christiansen J, Andersen E, Nielsen $A L$, et al. Association between late effects assessed by physicians and quality of life reported by head-and-neck cancer survivors. Acta Oncol. 2017;56(2):342-7.

20. Langius JA, Doornaert P, Spreeuwenberg MD, Langendijk JA, Leemans $C R$, van van der Bokhorst-de Schueren MA. Radiotherapy on the neck nodes predicts severe weight loss in patients with early stage laryngeal cancer. Radiother Oncol. 2010;97(1):80-5. https://doi.org/10.1016/j.radon c.2010.02.017.

21. Noori AGM, Al-Rawaq KJ, Al-Nuaimi DSA, Fattah MAN. Quality of life during head and neck external beam radiotherapy. Med Sci. 2019;23(95):125-9.

22. Maurer J, Hipp M, Schäfer C, Kölbl O. Dysphagia. Strahlenther Onkol. 2011;187(11):744-9.

23. Khan MK, Patterson J, Owen S, Rees S, Gamberini L, Paleri V, et al. Comparing the Performance Status Scale and MD Anderson Dysphagia Inventory as swallowing outcome measures in head and neck cancer: a prospective cohort study. Clin Otolaryngol. 2015;40(4):321-6. https://doi.org/10.1111/ coa.12369.

24. Wilson JA, Carding PN, Patterson JM. Dysphagia after nonsurgical head and neck cancer treatment:patients' perspectives. Otolaryngol Head Neck Surg. 2011;145(5):767-71. https://doi.org/10.1177/0194599811414506 (PubMed PMID: 21746839).

25. Chen AY, Frankowski R, Bishop-Leone J, Hebert T, Leyk S, Lewin J, et al. The development and validation of a dysphagia-specific quality-of-life questionnaire for patients with head and neck cancer: the MD Anderson dysphagia inventory. Arch Otolaryngol Head Neck Surg. 2001;127(7):870-6.

26. Andrade MS, Goncalves AN, Guedes RL, Barcelos CB, Slobodticov LD, Lopes SA, et al. Correlation between swallowing-related quality of life and videofluoroscopy after head and neck cancer treatment. CoDAS. 2017;29(1):e20150175. https://doi.org/10.1590/2317-1782/20172015175.

27. Hutcheson KA, Barrow MP, Lisec A, Barringer DA, Gries K, Lewin JS. What is a clinically relevant difference in MDADI scores between groups of head and neck cancer patients? Laryngoscope. 2016;126(5):1108-13. https:// doi.org/10.1002/lary.25778. 
28. Egestad $\mathrm{H}$, Nieder $\mathrm{C}$. Undesirable financial effects of head and neck cancer radiotherapy during the initial treatment period. Int J Circumpolar health. 2015;74(1):26686.

29. Llewellyn CD, Horney DJ, McGurk M, Weinman J, Herold J, Altman K, et al. Assessing the psychological predictors of benefit finding in patients with head and neck cancer. Psycho-Oncology. 2013;22(1):97-105.

\section{Publisher's Note}

Springer Nature remains neutral with regard to jurisdictional claims in published maps and institutional affiliations.
Ready to submit your research? Choose BMC and benefit from:

- fast, convenient online submission

- thorough peer review by experienced researchers in your field

- rapid publication on acceptance

- support for research data, including large and complex data types

- gold Open Access which fosters wider collaboration and increased citations

- maximum visibility for your research: over $100 \mathrm{M}$ website views per year

At BMC, research is always in progress.

Learn more biomedcentral.com/submissions 